\title{
Training programming: revisiting terminology
}

\author{
Mário C. Marques*
}

EDITORIAL

Does the way the literature presents the classic periodization or programming make sense? In our opinion, the answer is clearly no. To get started, periodization and programming are terms used interchangeably (as synonyms) in scientific literature when they actually have different meanings. Thus, to periodize is to set periods for a process (e.g., to a season or the sports life), whereas programming is defined as to devise and order the necessary actions to carry out a project. Accordingly, coaches and physical conditioning professionals should divide or periodize the season in different cycles and then, within each cycle, programming the training sessions. The periodization should not only help to structure the training process, but also to express the goals to achieve, to control the training process evolution and allow a great execution of the action plan.

When designing a plan, we simply organize all the "ingredients" that should be part of the work/training design in a concrete and detailed way. From a scientific point of view, the programming is nothing more than an adequate interpretation of the training biological laws (Tschione, 1992; Latonov, 1997, Issurin, 2008) and must have the performance improvement as the major reference criteria (Issurin 2010). In practice, during the last decades, we have followed a set of instructions mainly based on experienced coaches (Matveyev, 1981, Bompa, 1994, Zatsiorsky, 1995) who have obtained relevant results. As a consequence, it is very difficult to accept another solid scientific based vision or proposal since the accumulation of systematic experiences has led to the construction of a theoretical model, even though there are no scientific evidences.

The multiplication and implementation of the traditional programming models (Matveyev, 1981, Bompa, 1994) have guided us to a set of erroneous terms, among which we highlight the "micro", the "meso" and the "macro" cycles, that were never widely defined or justified in literature. In fact, these terms have caused confusion in the day-to-day training and in the academic community, arising many different visions about the same term. By instance, we can assume that a macro cycle can have duration of $4,6,8,12$ weeks or even a year. Nevertheless, the problem of training programming lies not in the way how the training period is called, but in its real meaning, that is, the way of organizing and monitoring the training load in order to reach the best physical shape, and if that is possible, within the defined deadline. In connection with the above, it would be even more inappropriate to use the ATR terminology (accumulation, transformation and realization) or the terms "integrated" or "concentrated" related to the training cycle because they lead many trainers to put these in practice, misleading them to think they are making a good planning. To the best of our knowledge, we do not know any study analyzing or providing scientific evidences that allow us to know with precision what, how and when the athletes concretely accumulate, transform and realize a set of physical and physiological strength or endurance variables, or any other motor skills, during training period. Thus, these terms never should be used because they are false, add nothing new to training process and are inappropriate to denominate biological processes, types of training or effects of such training programs. In fact, the aim of all training sessions is (or should be) to accumulate, transform (or rather, transfer) and realize continuously training stimuli that allows improve the physical performance of athletes. For these reasons, it is meaningless to say about a physical capacity that it is firstly accumulated, then it is transformed (or transferred) and finally it is realized. Only an atrocious ignorance of the basic physiological fundamentals of adaptation, and goals and principles of training, could originate such a misconception and that these theories/conjectures are transformed in universal laws to the service of the training.

* Corresponding author: Departamento de Ciências do Desporto da UBI, Rua Marquês Ávila e Bolama, 6201001, Covilhã, Portugal. E-mail: mmarques@ubi.pt 
Therefore, one of the major problems related to the design and programming of the training is that there exists an extensive, inappropriate and confused terminology, which does not help, per se, the correct organization of training loads and its implementation through concrete exercises.

Based on the above, we propose a bigger simplification of the terminology when we mention the training cycles. So, when we refer to the "cycle", we are talking specifically about the extension of a certain period of time, which represents a periodic process repeated in an estimated time span. In this regard, a training cycle should express a set of training phases with certain characteristics that are repeated periodically, whose purpose is always the improvement of sports performance or of one or more motor skills. A "complete cycle" of training is the one where all the possible phases of a cycle are defined, which will be more or less numerous according to the features and the theory/ model adopted for the training programming.

When the development of several physical capacities plays a significant role in the improvement of a certain sport discipline, the features of each training phase become more pronounced, with higher training intensity and/or volume. The opposite occurs when these sports needs are moderate or low. It should be further noted that each phase has its own specific goal that doesn't vary much from the general goal. However, the way of developing each phase would be different according to the sport discipline, sport expertise, training background and the features of each individual.
In our opinion, the load distribution throughout the training cycles is the content that has been scientifically less developed during the last couple of years. Many ways of programming have been proposed, with none or few scientific backups. Thus, we think that the way to truly perform a suitable training programming is focusing each training session in important matters such as the level and type of stress caused by each training stimulus, the necessary period of recovery between training sessions, the ability to recover for each individual and the time during which a stimulus is effective.

\section{REFERENCES}

Bompa, T. (1984). Theory and methodology of training: the key to athletic performance. Boca Raton: Kendall Hunt.

Issurin, V. B. (2010). New horizons for the methodology and physiology of training periodization. Sports Medicine, 40(3), 189-206.

Issurin, V. B. (2008). Principles and basics of advanced training of athletes. Muskegon: Ultimate Athletes Concepts Publisher.

Latonov, V. N. (1997). General theory of athletes' preparation in the Olympic sports. Kiev: Olympic Literature.

Matveyev, L. P. (1981). Fundamental of sport training. Moscow: Progress Publishers.

Tschiene, P. (1992). The priority of the biological aspect in the theory of training. Adelaide: South Australian Sports Institute.

Zatsiorsky, V. M. (1995). Science and practice of strength training. Champaign: Human Kinetics.

Zheliazkov, T. (1981). Theory and methodology of sport training: textbook for Sport University. Sofia: Medicina i Fizcultura. 